\title{
Archéopages
}

Archéopages

Archéologie et société

Hors-série 2 | 2010

Archéologie sans frontières

\section{La céramique du tumulus de Tater Gur et ses apports pour la connaissance du Haut-Moyen Âge en Éthiopie}

\section{Alain Wittmann}

\section{CpenEdition}

\section{Journals}

Édition électronique

URL : https://journals.openedition.org/archeopages/754

DOI : 10.4000/archeopages.754

ISSN : 2269-9872

Éditeur

INRAP - Institut national de recherches archéologiques préventives

Édition imprimée

Date de publication : 1 octobre 2010

Pagination : 40-43

ISSN : $1622-8545$

Référence électronique

Alain Wittmann, «La céramique du tumulus de Tater Gur et ses apports pour la connaissance du Haut-Moyen Âge en Éthiopie », Archéopages [En ligne], Hors-série 2 | 2010, mis en ligne le 01 octobre 2010, consulté le 23 février 2023. URL : http://journals.openedition.org/archeopages/754; DOI : https://doi.org/10.4000/archeopages.754 


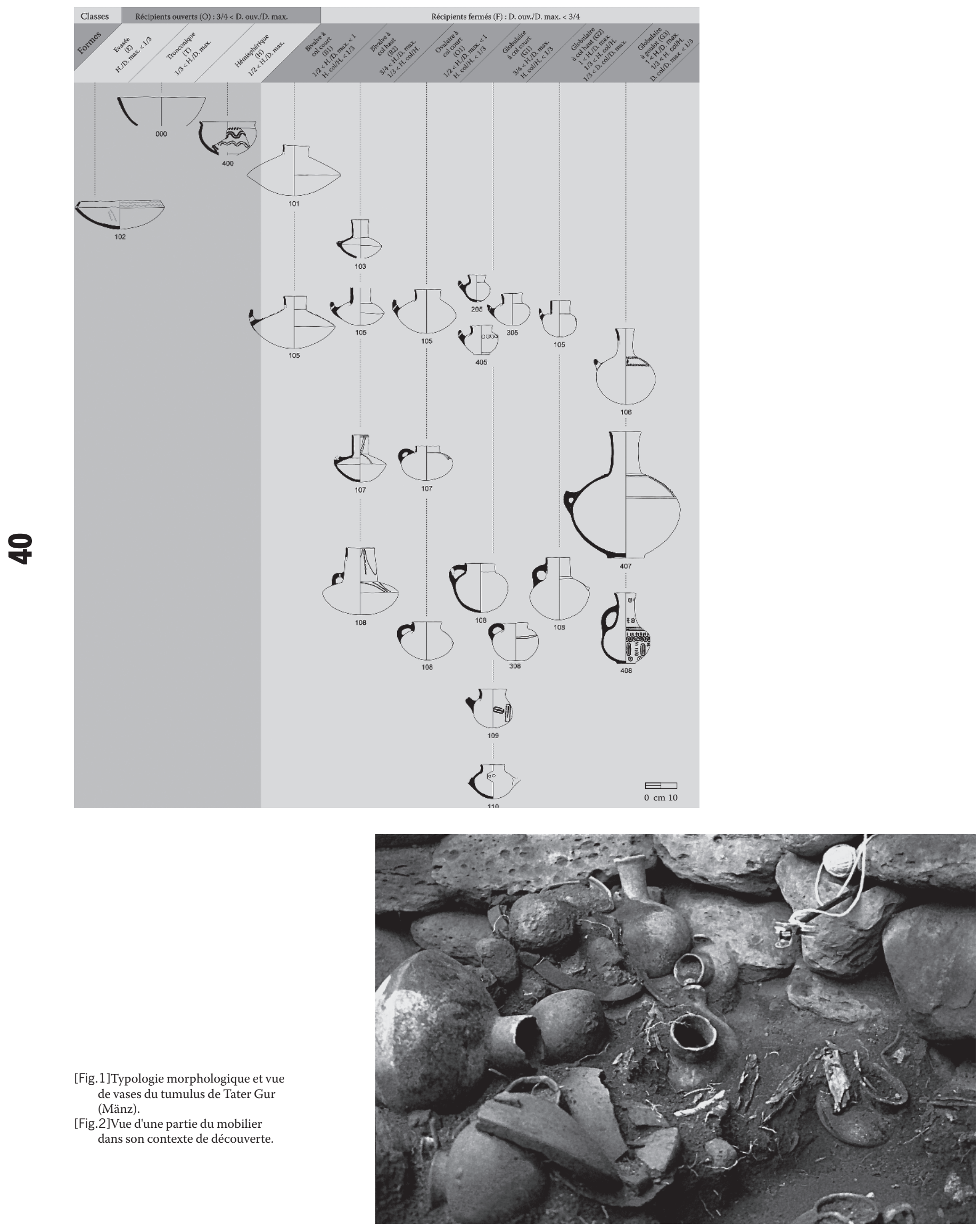


pèlerinage et nécropole sur une longue durée. Les sondages entrepris dans les tas de déblais à Lalibela ont confirmé les observations réalisées l'année précédente sur les étapes de creusement en mettant en évidence différents niveaux de sol qui témoignent des moments de creusement et d'occupation du site. Le travail archéologique est, dans ce cas, mené en parallèle aux recherches historiques dans les archives conservées sur le site à partir du XIII ${ }^{\mathrm{e}}$ siècle. Il apparaît aujourd'hui que Lalibela ne résulte pas d'un programme mené d'un seul tenant, mais d'interventions répétées au cours de plusieurs siècles et qui n'ont pas cessé de modifier le site.

Les recherches archéologiques en Éthiopie, pour les périodes historiques, doivent beaucoup à la collaboration de l'Inrap avec le Centre français des études éthiopiennes. Toutes les campagnes de fouilles menées dans le cadre de cette collaboration ont non seulement ouvert de larges perspectives pour la recherche, mais aussi permis de constituer les premières collections de référence pour l'architecture, le funéraire, la céramique ou pour le lithique. La capacité des archéologues de l'Inrap à s'adapter à tous types de terrain, à fouiller tous types d'époque et de cultures s'avère d'une valeur inestimable. Cette collaboration est essentielle pour combler les lacunes de la recherche sur l'Éthiopie ou sur l'Afrique en général, un domaine dans lequel trop peu d'archéologues sont formés en France, alors qu'il s'agit d'une aire géographique dont le potentiel est immense en terme de découvertes.

CASSEN S., 1995, «Une enquête ethnoarchéologique sur la production céramique de Haro (Éthiopie) ", in Joussaume R. (DIR.), Tiya. l'Éthiopie des mégalithes. Du biface à l'art rupestre dans la Corne de l'Afrique, Chauvigny, Association des Publications Chauvinoises, Mémoire XI, p. 358-373.

Derat M.-L., JouQUAND A.-M.(DIR.), à paraitre : Gabriel, une église médiévale d'Éthiopie. Interprétations historiques et archéologiques de sites chrétiens autour de Meshala Māryām (XV'-XVII ${ }^{\mathrm{e}}$ siècles).

Fauvelle-Aymar F.-X., Ayenachew D., Hirsch B., Bernard R., 2007-2008, «Les monuments mégalithiques du Mänz (nord-Shoa) un inventaire provisoire ", Annales d'Éthiopie, vol. XXIII, p. 329-398.

Hirsch B., Poissonnier B., 200o, « Recherches historiques et archéologiques à Meshalä Māryām (Mänz, Éthiopie) : résultats préliminaires ", Annales d'Éthiopie, 16, p. 59-88.

MunRo-HAY S.C. (DIR.), 1989, Excavations at Aksum. An account of research at the ancient Ethiopian capital directed in 1972-74 by the late Dr Neville Chittick, Londres, British Institute in Eastern Africa, Memoir 10, $359 \mathrm{p}$.

Roux H. DE, 1976, « Aperçu sur la fabrication de la poterie à Yéha (Tigré) », Annales d'Êthiopie, 10, p. 305-320.

\section{La céramique du tumulus de Tater Gur et ses apports pour la connaissance du Haut-Moyen Âge en Éthiopie}

Alain Wittmann

$$
\text { Inrap }
$$

Si le Haut-Moyen Âge éthiopien représente un hiatus dans l'histoire du pays en raison de la rareté des sources écrites, la même méconnaissance pèse sur sa culture matérielle : les sites archéologiques de cette période restent rares et les études de référence sur le mobilier font largement défaut. La fouille récente du tumulus de Tater Gur, dont le fonctionnement a pu être daté entre la fin du $\mathrm{VIII}^{\mathrm{e}}$ et le début du $\mathrm{X}^{\mathrm{e}}$ siècle par une série d'analyses au radiocarbone, s'impose donc comme une étape essentielle dans ce domaine de recherche. Cette tombe privilégiée, constituée d'un couloir d'accès et d'une chambre circulaire architecturés, a livré un dépôt de vases dont l'abondance, l'homogénéité et le remarquable état de conservation justifiaient une étude approfondie. L'ensemble céramique a ainsi offert l'opportunité, non seulement de poser un premier jalon dans l'analyse du répertoire typologique et décoratif régional (culture « Shay »), mais aussi d'aborder des problématiques plus vastes concernant son lien avec les rites funéraires et l'origine géographique de son faciès.

Approches technique et typologique. La mise en parallèle de ce corpus avec des enquêtes ethnographiques conduites sur les sites de production actuels ont permis de restituer, au moins partiellement, la chaîne opératoire qui a présidé au façonnage des vases. En revanche, de nombreux problèmes se posent encore sur l'identification des outils naturels ou anthropiques, voire sur les procédés mis en ouvre pour la réalisation des différentes catégories de décor. Nous avons ensuite élaboré une typologie du mobilier indépendamment de toute considération d'ordre fonctionnel, dans la mesure où la question de l'usage des vases est peu documentée en ethnoarchéologie africaine ; on peut également observer que les céramiques éthiopiennes employées de nos jours n'assurent pas nécessairement une fonction spécifique, mais servent souvent de contenants polyvalents, au point de rendre inopérante la distinction habituelle entre vases à liquides et vases à solides. Le système de classification hiérarchique adopté repose donc uniquement sur des critères morphologiques et métrologiques. Ainsi, les différentes formes se définissent par des rapports de dimensions échafaudés à partir de mesures simples, telles que la hauteur totale, la hauteur du col, le diamètre maximal et le diamètre à l'ouverture [Fig.1]. Bien que cette méthodologie ait été surtout développée pour des productions tournées fortement standardisées, son champ d'application peut s'étendre aux céramiques modelées de Tater Gur, car ces dernières obéissent malgré tout à certaines règles élémentaires de géométrie et se répartissent en séries relativement homogènes. Lavantage majeur d'un tel classement est de fournir une structure ouverte, qui autorisera à tout moment l'intégration de formes et de types nouveaux provenant d'autres sites contemporains de la région du Mänz.

Approches culturelles. Pour l'heure, le rôle, le choix et le traitement de la céramique dans l'appareil funéraire offrent peu de prises à l'interprétation. Les récipients n'avaient-ils qu'une valeur strictement symbolique ou contenaient-ils des denrées alimentaires ? Étaient-ils uniquement destinés au mort et à sa survie dans l'au-delà, ou bien servaient-ils aux vivants pour accomplir leurs 


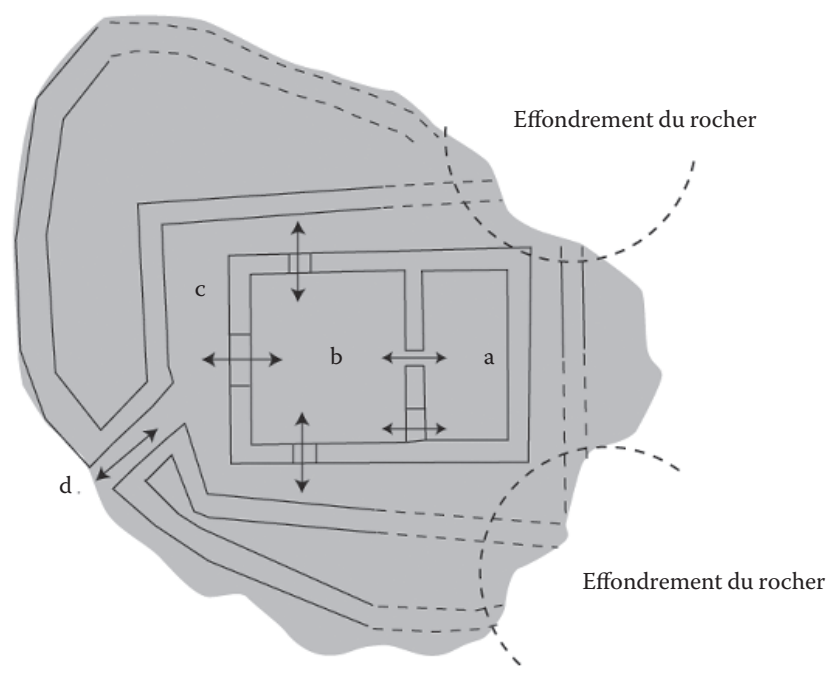

Sépultures et fosses non fouillees
postérieures à la destruction de l'église

Sépultures et fosses fouillées et

postérieures à la destruction de l'église WIII/I, Sépulture F10 antérieures à l'église

Poteau ou planche en bois

$\mathcal{Y}$

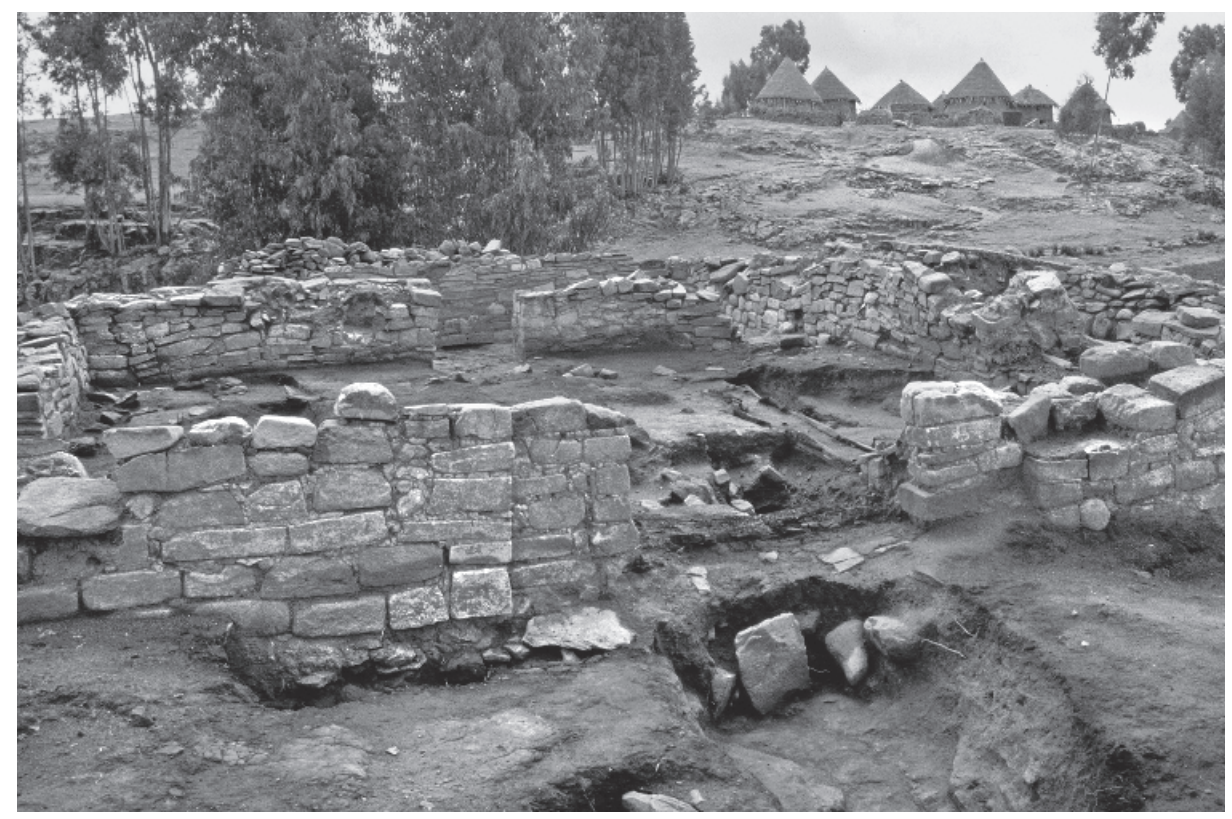

[Fig.1] Plan restitué de l'église Gabriel.

[Fig.2] Plan général des vestiges observés.

[Fig.3] Entrée occidentale de la nef. 